\title{
A Smart IoT Fuzzy Irrigation System
}

\author{
George Kokkonis ${ }^{1}$, Sotirios Kontogiannis ${ }^{2}$, Dimitrios Tomtsis ${ }^{1}$ \\ ${ }^{l}$ Dept. of Business administration, Western Macedonia University of Applied Studies, Greece, \\ (gkokkonis,tomtsis)@teiwm.gr \\ ${ }^{2}$ Dept.of Mathematics, University of Ioannina, Greece, skontogiannis@cc.uoi.gr
}

\begin{abstract}
This paper proposes a novel fuzzy computational algorithm for IoT smart irrigation systems. It describes all the possible sensors, actuators and microcontrollers that could be used in the irrigation systems. Based on these sensors a novel system architecture is presented. The irrigation system continuously monitoring air temperature and humidity, and ground moisture. The ground humidity sensors are interspersed all over the field. The measurements are send in a microcontroller that applies a fuzzy computational algorithm and decides whether to open a servo valve or not. All the data collected from the microcontroller are sent to a cloud database for statistical information and processing.
\end{abstract}

Keywords: Iot, irrigation systems, fuzzy algorithms, precision farming.

\section{INTRODUCTION}

Water scarcity is on one of the major concerns of today's agriculture. Efficient irrigation of agricultural land could be accomplished with the help of smart irrigation systems. Smart irrigation systems have as primary goal the minimization of water consumption and the maximization of quantity and the quality of the crops. A trade of between these three amounts could be made [1]. Another concern that irrigation systems have is the power consumption of the system. As most of agricultural land is located in isolated places without stable electrical powerline the power of the system is an important factor. Smart irrigation systems use actuators and sensors to control the ground moisture of the agricultural land. The data collected from the sensors could be send through the Internet of Things (IoT) to data servers for statistical information and processing. On this basis we propose our smart - fuzzy irrigation system of arable areas. With the help of multiple soil moisture sensors, effective irrigation of agricultural land that increase production and minimize water consumption is achieved. A fuzzy computational algorithm is proposed that determines the amount of the opening of the central servo valve of the irrigation system. This fuzzy algorithm has as input interspersed in the field multiple soil moisture sensors. Soil moisture is constantly monitored. The data collected from the sensors is sent to server for statistical analyses. The rest of the paper is organized as follows. Section 2 outlines the related work on smart irrigation systems. Section 3 presents the wireless technologies that are used in IoT irrigation systems. Section 4 describes the sensors and the actuators that our irrigation system uses. Section 5 presents the proposed system architecture of our system. Section 6 analyzes the proposed fuzzy watering algorithm. Section 7 identifies conclusions and future work.

\section{RELATED WORK}

A smart IoT fuzzy irrigation system is defined as a system that controls field irrigation without user interference. The decision for watering is based on data that are collected through the Internet of Things (IoT) from weather websites and with the help of sensors and actuators. Based on the process for the watering decision the irrigation systems are divided into the IoT weather based irrigation systems and the sensor based irrigation systems. In the weather based irrigation systems the decision for irrigation is taken based on future weather conditions that are collect through the Internet. The system gathers data for temperature, rain, air humidity, [2]. Based on the data that are gathered the decision for irrigation is made. The system monitor the air temperature in order to avoid irrigation in extreme weather conditions, as if the temperature drops down $0{ }^{\circ} \mathrm{C}$, so as to prevent the plants from freezing. Furthermore the system monitors the rain fall in the close future in order to avoid irrigation and save water if rain is about to start. Moreover, humidity and wind measurements are needed to estimate the dehydration of the plants [3]. The system accesses the Internet through 4G/3G/GPRS gateways and it collects the data from weather websites [4]. All the data gathered from the websites are stored in databases for future processing. Smart phones play a major role in these systems as the farmer is informed through its phone for notifications and alerts from the system[5]. 
Another system architecture for smart irrigation systems is based on sensors that are placed in the field. They monitor soil moisture with the help of ground humidity sensors [6] and try to decide if the field needs irrigation or not. This type of irrigation systems outperform the weatherbased systems as the measure with precision the humidity of the field. The only disadvantage they have is that they cannot predict the weather in the close future. A hydride system that combines information for future weather conditions for website and close field environmental conditions from local sensors is a good solution for the proper irrigation of the field with as watering saving as possible [7]. Some smart irrigations systems have already been proposed. A smart irrigation system that uses a soil sensor and a central controller is offered by Koubachi company. A self-learning watering algorithm with statically assigned weights is used in [8]. An arduino based smart irrigation system was presented by Parameswaran and Sivaprasath. It monitors the PH, the temperature and the moisture levels in the field [9]. An Automation of Irrigation System based on Wi-Fi Technology and IOT was presented by Kranthi Kumar and Srenivasa [10]. Harun et al. proposed a IoT precision irrigation system for green houses with the help of a wireless sensor network [11].

Rajalakshmi and Mahalakshmi developed a system to monitor crop-field using sensors (soil moisture, temperature, humidity, Light) and automate the irrigation system. They used a NRF24L01 module for wireless data transmission between the field and the web server. They choose NRF24L01 because of the low power consumption. NRF24L01 requires 1.9-3.6V and uses 2.4GHz [23]. On the other hand Srishti Rawal proposes an automated irrigation system which monitors and maintains the desired soil moisture content via automatic watering. He choose GSM-GPRS SIM900A modem to update regularly a webpage through which a farmer can check whether the water sprinklers are ON/OFF at any given time. The GSM modem is a highly flexible plug and play quad bandSIM900. It Supports features like Voice, SMS, Data/Fax, GPRS and integrated TCP/IP stack [24].

\section{WIRELESS TECHNOLOGIES USED BY EXISTING IOT BASED SMART IRRIGATIONS SYSTEMS.}

For the purposes of proper and efficient operation of the smart irrigations systems, a wireless communications system capable of controlling the actuators and sensors is essential. This ability share RFM69, IEE802.15.4 Zigbee, LoRa and LoRaWaN technologies.

TABLE 1. The Comparative table of RFM69, IEEE 802.15 .4 Zigbee, LoRa and LoRaW
\begin{tabular}{|c|c|c|c|c|}
\hline & $\begin{array}{c}\text { RFM6 } \\
\mathbf{9}\end{array}$ & $\begin{array}{c}\mathbf{8 0 2 . 1 5 . 4} \\
\text { Zigbee }\end{array}$ & LoRa & LoRaWAN \\
\hline Frequency(MHz) & 433 & 2.400 & 433 & 868 \\
\hline Data rate (kbps) & $1.2-300$ & $20-250$ & $0.3-22$ \\
\hline $\begin{array}{c}\text { Transmit/ Receipt } \\
\text { Power (mW) }\end{array}$ & 100 & 63 & 25 \\
\hline $\begin{array}{c}\text { Coverage LOS } \\
\text { Distance (m) }\end{array}$ & 1.600 & $10-100$ & $2.000-5.000$ \\
\hline Topology & Star & $\begin{array}{c}\text { Tree, star or } \\
\text { mesh }\end{array}$ & Star-of-stars \\
\hline
\end{tabular}

RFM69 operates at $433 \mathrm{GHz}$. Can cover a star topology network within $1,6 \mathrm{Km}$. The data rate ranges between 1.2-300kbps, however, the power consumption for transmission and reception is higher than Zigbee and Lora. A much smaller surface of land (up to 100m) can serve the IEEE802.15.4 Zigbee. The Zigbee modules operate within the ISM $2.4 \mathrm{GHz}$ frequency band. A Zigbee network can be a star, tree or mesh topology. The MAC layer of Zigbee attempts to achieve energy saving by exclusive use of medium access control facilities so that higher layers in the protocol stack are unaffected and unaware of this. A typical LoRa or LoRaWAN network is a 'star-of-stars' topology. Both can cover the distance between $2-5 \mathrm{~km}$, i.e. much greater distance than that covered by the aforementioned technologies while consuming less power. The essential difference between Lora and LoRaWAN is, that LoRaWAN standardizes and extend the LoRa physical communication layer onto internet network. Based on Table 1 the critical factors for selecting the appropriate wireless technology are the necessary transmission range, the data rate and the power consumption. If the distance between the Internet gateway and the microcontroller is greater than 100 meters then IEEE 802.15.4 Zigbee should not be chosen. If the distance is greater than 5000 meters then the 3G/GPRS cellular network is the only solution. If the data rate of the irrigation system is greater than $22 \mathrm{kbps}$ then the LoRaWan technology should not be chosen. The authors in order to test the wireless technologies in various distances measured the signal power that RFM69, IEEE802.15.4 Zigbee, LoRa wireless modules transmit. The outcomes of these experiments for $50 \mathrm{~m}, 1500 \mathrm{~m}$ and $4000 \mathrm{~m}$ are depicted in Table 2, 3 and 4. 
TABLE 2. Signal Power for Cover Distance 50m

\begin{tabular}{|l|l|l|}
\hline Transceiver & Range $(\mathbf{m})$ & Signal Power $(\mathbf{d B m})$ \\
\hline RF69HCW & 50 & -45 \\
\hline SX1276 LoRa & 50 & -45 \\
\hline Xbee 63mW & 50 & -56 \\
\hline
\end{tabular}

TABLE 3. Signal Power for Cover Distance $1500 \mathrm{~m}$

\begin{tabular}{|l|l|l|}
\hline Transceiver & Range (m) & Signal Power (dBm) \\
\hline RF69HCW & 1500 & -94 \\
\hline SX1276 LoRa & 1500 & -89 \\
\hline Xbee 63mW & 1500 & - \\
\hline
\end{tabular}

TABLE 4. Signal Power for Cover Distance $4000 \mathrm{~m}$

\begin{tabular}{|l|l|l|}
\hline Transceiver & Range (m) & Signal Power (dBm) \\
\hline RF69HCW & 1500 & - \\
\hline SX1276 LoRa & 1500 & -104 \\
\hline Xbee 63mW & 1500 & - \\
\hline
\end{tabular}

It is obvious that if the distance range is shorter than $50 \mathrm{~m}$ all technologies transfer IoT data successfully. If the distance is close to $1500 \mathrm{~m}$ then only the SX1276 LoRa and the RF69HCW module manage to transfer data. If the distance range is equal to 4000m only the SX1276 LoRa module manage to transfer data.

\section{SENSORS, ACTUATORS AND MICROCONTROLLERS IN SMART IRRIGATION SYSTEMS}

The sensors, the actuators and the microcontrollers that are usually used in a smart irrigation system , are the following:

1. Arduino microcontroller. It is a single board microcontroller that collects the data from the sensors. It is responsible to perform statistical analysis and controls in order to decide whether to open the valve for watering or not. It has multiple digital and analog input and output pins and consumes little power energy. All the sensors, the actuators and the data transceivers are connected to the microcontroller. If the control unit demands more computational power then the Raspberry Pi microcomputer is proposed [14]. In that case a analog to digital (A2D)converter is used since the RPi doesn't have analog inputs. A common A2D converter is the MCP3008.

2. Water flow sensors. These sensors help the microcontroller to measure the amount of water that is used for irrigation. The amount of the water depends on the water pressure, the diameter of the pipe and the watering time.

3. Soil moisture sensors [13]. These sensors measure the moisture of the ground. They are placed near the roots of the plant in order to be more accurate. They are analog or digital sensors. Their value range is [0..1024]. As ground humidity varies from place to place, multiple soil moisture sensors are used, in order to have a safer outcome. Figure 1 depicts the sensitivity and border conditions of two soil moisture sensors over rainfall that are placed in two diagonal edges of one square meter flat test-bed field. These sensors should be calibrated in order to establish the desirable moisture.

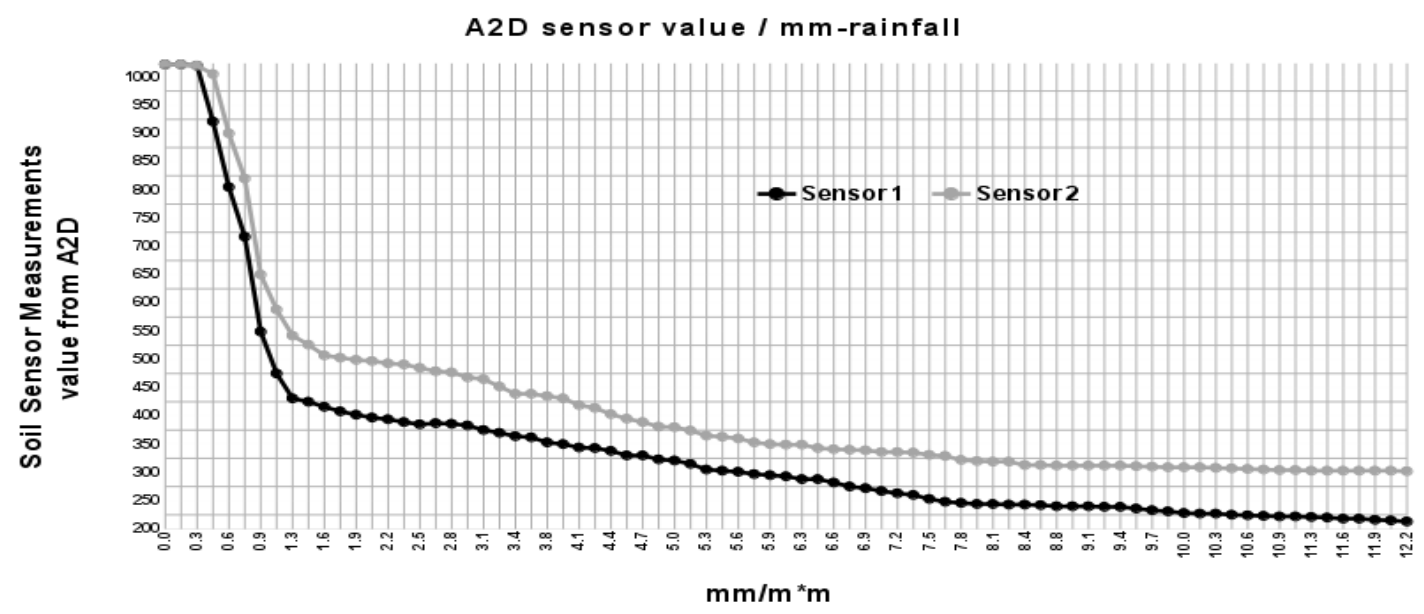


Figure 1. Soil sensors measurements over rainfall placed in two diagonal edges of a flat 1 square meter test-bed field

4. Temperature sensors. These sensors are used to measure the air temperature. The air temperature give important date in order to calculate the dehydration of the plants. Many plants are sensitive to air temperature during irrigation. Especially in extreme weather conditions, very hot or very cold, the irrigation should be avoided.

5. Air humidity sensors. Air humidity is also a crucial factor for plant dehydration. Air humidity also affects growth, flowering, and water relations of the plants.

6. The water valve. It is responsible for opening and closing the water flow. It is controlled from the microcontroller with the help of a power mosfet transistor switch. If the water systems under pressure, then a solenoid valve is often used. If we want to control the water flow then a servo valve is chosen.

7. Internet gateway. If the field is located in a remote location then the $4 \mathrm{G} / 3 \mathrm{G} / \mathrm{GPRS}$ network is used to access the internet. In that case a $3 \mathrm{G}$ dongle/shield is used to connect the microcontroller to the cloud. If the field is close to an Internet gateway, then other communication technologies, as Bluetooth LE, Zigbee and WiFi, could be chosen. The wireless technology that is chosen is based on Table 1.

8. Power system. Since most of the field do not have a power line available, the solar energy is often chosen. A solar system is composed by a solar panel, a battery and a charge regulator. Since the input voltage of its component is deferent, DC-DC duck or boost step up voltage regulators are used to change the available input voltage. If the field is connected to the powerline then a simple AC-DC voltage adapter is used.

\section{PROPOSED SYSTEM ARCHITECTURE OF THE IRRIGATION SYSTEM}

The proposed system architecture of the irrigation system is depicted in Figure 2. The structural parts of the watering system as the microcontroller, the sensors, the actuators and the internet gateway and the power system are demonstrated. All the individual parts of the system architecture are analyzed in the previous section.

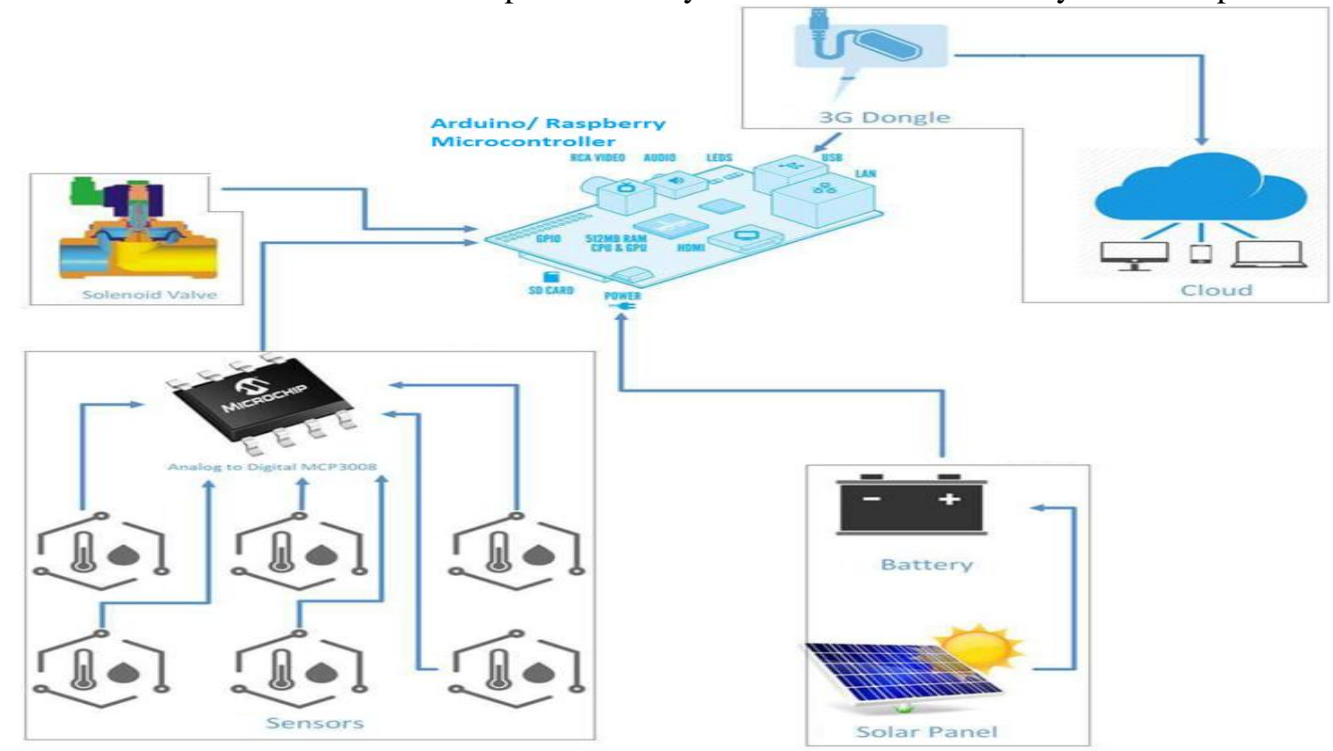

Figure 2. High Level System Architecture of a Smart Irrigation System.

\section{THE FUZZY PROPOSED WATERING SYSTEM ALGORITHM}

\section{A. Input- Outputs}

As the above system has multiple sensors and as input and one actuator, the valve, as output there must be an algorithm that decides when the valve should open, how much should be opened and when to close. The authors propose a fuzzy algorithm for the control of the watering valve.

As input the system has:

- $\quad$ eight ground moisture sensors scattered in the field.

- One air humidity sensor.

- One temperature sensor

As output the system has:

- One servo valve that irrigates the field.

B. Membership Functions

As membership function for all the inputs we used the Gaussian function. 
For the eight ground moisture sensors the state, the range, the Standard Deviation, the mean value for the gaussian function are given to Table 5 .

TABLE 5. Membership Functions of the ground moisture sensors.

\begin{tabular}{|l|l|l|l|l|l|}
\hline Sensor & $\begin{array}{l}\text { Name } \\
\text { of MF }\end{array}$ & $\begin{array}{l}\text { Membership } \\
\text { function }\end{array}$ & Range & $\begin{array}{l}\text { Standard } \\
\text { Deviation }\end{array}$ & $\begin{array}{l}\text { Mean } \\
\text { value }\end{array}$ \\
\hline $\begin{array}{l}\text { Ground moisture } \\
\text { sensors }\end{array}$ & Dry & Gaussian & {$[0-1024]$} & 256 & 0 \\
\hline $\begin{array}{l}\text { Ground moisture } \\
\text { sensors }\end{array}$ & Normal & Gaussian & {$[0-1024]$} & 256 & 512 \\
\hline $\begin{array}{l}\text { Ground moisture } \\
\text { sensors }\end{array}$ & Wet & Gaussian & {$[0-1024]$} & 256 & 1024 \\
\hline
\end{tabular}

For the temperature sensor the state, the range, the Standard Deviation, the mean value for the gaussian function are given to Table 6

TABLE 6. Membership Functions of the temperature sensor.

\begin{tabular}{|l|l|l|l|l|l|}
\hline Sensor & $\begin{array}{l}\text { Name } \\
\text { of MF }\end{array}$ & $\begin{array}{l}\text { Membership } \\
\text { function }\end{array}$ & Range & $\begin{array}{l}\text { Standard } \\
\text { Deviation }\end{array}$ & $\begin{array}{l}\text { Mean } \\
\text { value }\end{array}$ \\
\hline Temperature sensor & Cold & Gaussian & {$[-20,40]$} & 15 & -20 \\
\hline Temperature sensor & Normal & Gaussian & {$[-20,40]$} & 15 & 10 \\
\hline Temperature sensor & Hot & Gaussian & {$[-20,40]$} & 15 & 40 \\
\hline
\end{tabular}

For the humidity sensor the state, the range, the Standard Deviation, the mean value for the gaussian function are given to Table 7 .

TABLE 7. Membership Functions of the temperature sensor.

\begin{tabular}{|l|l|l|l|l|l|}
\hline Sensor & $\begin{array}{l}\text { Name } \\
\text { of MF }\end{array}$ & $\begin{array}{l}\text { Membership } \\
\text { function }\end{array}$ & Range & $\begin{array}{l}\text { Standard } \\
\text { Deviation }\end{array}$ & $\begin{array}{l}\text { Mean } \\
\text { value }\end{array}$ \\
\hline Humidity sensor & Dry & Gaussian & {$[0,100]$} & 25 & 0 \\
\hline Humidity sensor & Normal & Gaussian & {$[0,100]$} & 25 & 50 \\
\hline Humidity sensor & Wet & Gaussian & {$[0,100]$} & 25 & 100 \\
\hline
\end{tabular}

For the output of the Fuzzy system there was the opening of the servo valve. The range of the degrees that a servo valve can be opened are $[0,90]$. There were three state of our valve based on Table 8. The function that described the opening of the servo valve was the triangle function.

TABLE 8. Membership Functions of the Servo valve.

\begin{tabular}{|l|l|l|l|l|}
\hline Output & Name of MF & Membership function & Range & MF Parameters \\
\hline Servo valve & Close & Trapezoid-Shaped & {$[0,90]$} & {$[-1,0,30,45]$} \\
\hline Servo valve & Half -open & Triangle & {$[0,90]$} & {$[30,45,60]$} \\
\hline Servo valve & Open & Trapezoid-Shaped & {$[0,90]$} & {$[45,60,90,91]$} \\
\hline
\end{tabular}

C. Rules

The rules of the Fuzzy system are set with the help of the farmer. The general rule of the Fuzzy irrigation system are given to Table 9.

TABLE 9. Membership Functions of the Servo valve.

\begin{tabular}{|l|l|l|}
\hline Input Parameters & Output & State \\
\hline $\begin{array}{l}\text { More than 3 Ground moisture } \\
\text { sensors are Dry }\end{array}$ & Servo valve & Open \\
\hline Temperature sensor is Cold & Servo valve & Close \\
\hline $\begin{array}{l}\text { Less than 4 Ground moisture sensors } \\
\text { are Normal and Temperature sensor } \\
\text { is Hot and Humidity Sensor is Dry }\end{array}$ & Servo valve & Half -open \\
\hline $\begin{array}{l}\text { Less than 4 Ground moisture sensors } \\
\text { are Dry and Temperature sensor is } \\
\text { Hot and Humidity Sensor is Dry }\end{array}$ & Servo valve & Open \\
\hline Less than 3 Ground moisture sensors & Servo valve & Half -open \\
\hline
\end{tabular}


are Dry and Temperature sensor is

Hot and Humidity Sensor is Dry

In all other combinations of the input values the Servo valve is closed. As a defuzzification method, the center of gravity of the set is chosen.

\section{CONCLUSIONS}

This paper presents a smart IoT Fuzzy irrigation system. It uses low-cost off the shelf sensors and actuators for continuously monitoring environmental conditions of arable areas. Our system proposes an integrated solution that maximizes the quality and the quantity of the agriculture production. Air temperature, moisture and soil humidity are continuously monitored. With the help of servo valve the ground humidity is controlled. The high-level architecture of the system and its individual parts are presented and analyzed. It is based on open source programming environments and languages such as Linux, PHP, and MySQL. Moreover, a novel fuzzy computational algorithm responsible for water irrigation is proposed. As input for that algorithm has the air humidity and temperature and the soil moisture from multiple ground humidity sensors. Each of the input has three levels in the fuzzy system. The output of the algorithm controls the opening of the central servo valve of the irrigation system.

\section{REFERENCES}

[1] S. R. Kumbhar, Arjun P. Ghatule, "Microcontroller based Controlled Irrigation System for Plantation", Proceedings of the International Multi Conference of Engineers and Computer Scientists, Vol. 2, March 2013.

[2] Halahan, P. B., McIntyre, J. P., Coopersmith, M., \& Puckett, M., "System and Method for Smart Irrigation", U.S. Patent Application No. 14/612,229, 2015

[3] Ko, J., \& Piccinni, G. (2009). "Corn yield responses under crop evapotranspiration-based irrigation management.", Agricultural Water Management, vol. 96, pp 799-808., 2009

[4] Allen, R. G., Pereira, L. S., Raes, D., \& Smith, M., "Crop evapotranspiration-Guidelines for computing crop water requirements FAO Irrigation and drainage paper 56.", FAO, Rome, 300(9), D05109, 1998

[5] Migliaccio, K. W., Morgan, K. T., Fraisse, C., Vellidis, G., \& Andreis, J. H. (2015). Performance evaluation of urban turf irrigation smartphone app.Computers and Electronics in Agriculture, 118, 136142.

[6] Majone, B., Viani, F., Filippi, E., Bellin, A., Massa, A., Toller, G., ... \& Salucci, M. (2013). Wireless sensor network deployment for monitoring soil moisture dynamics at the field scale. Procedia Environmental Sciences, 19, 426-435.

[7] Navarro-Hellín, H., Martínez-del-Rincon, J., Domingo-Miguel, R., Soto-Valles, F., \& Torres-Sánchez, R. (2016). A decision support system for managing irrigation in agriculture. Computers and Electronics in Agriculture, 124, 121-131.

[8] Koubachi Company., "The Plant Sensor for your Home and Garden", April 2015.

[9] Parameswaran, G., and K. Sivaprasath. "Arduino Based Smart Drip Irrigation System Using Internet of Things.", International Journal of Engineering Science, vol 5518, 2016.

[10] Kumar, M. Kranthi, and Srenivasa Ravi. K., "Automation of Irrigation System based on Wi-Fi Technology and IOT.", Indian Journal of Science and Technology, vol. 9, issue 17, 2016.

[11] Harun, A. N., Kassim, M. R. M., Mat, I., \& Ramli, S. S., "Precision irrigation using Wireless Sensor Network."IEEE Int. Conf. on. Smart Sensors and Application (ICSSA 2015), pp. 71-75, 2015.

[12] FAO Corporate Document Repository, "Irrigation Water Management: Training Manual No. 1 Introduction to Irrigation", June 1985.

[13] LU, Rong-jian, Pin Li, and Zhou Sun. "Application of SHT10 sensor in humidity-and-temperature monitoring system", Transducer and Microsystem Technologies vol 9, pp 0-40, 2012.

[14] Raspberry Pi Foundation. The raspberry pi, the low cost embedded hardware computer system, 2011.

[15] Gardena soil moisture sensor, An automatic water saving irrigation component for small field irrigation, http://www.gardena.com/int/water-management/water-controls/soil-moisture-sensor, 2015.

[16] Hunter Industries, Soil clik moisture sensor irrigation system, http://www.hunterindustries.com/irrigationproduct/sensors/soil-cliktm,2014.

[17] Mihajlov, B., and Bogdanoski, M.."Overview and Analysis of the Performances of ZigBeebased Wireless Sensor Networks", International Journal of Computer Applications, vol. 29, no. 12, 2011.

[18] Augustin, A., Yi, J., Clausen, T., and Townsley, W. M. (2016). "A Study of LoRa: Long Range \& Low Power Networks for the Internet of Things", Sensors, 16, 1466. 
[19] Baronti, P., Pillai, P., Chook, V.W.C.,Chessa, S., Gotta A., Hu, Fun Y.. "Wireless sensor networks: A survey on the state of the at and the 802.15.4 and ZigBee standards", Computer Communications 30, 1655-1695, 2007

[20] ZigBee Alliance, "ZigBee Specification", ZigBee Document 053474r17, 2008

[21] Orange Connected Objects \& Partnerships, "LoRa Device Developer Guide", 2016

[22] Lora Alliance, "LoRaWAN- What is it?- A technical overview of LoRa and LoRaWAN", 2015

[23] Rajalakshmi, P., Mahalakshmi, S. D., "IOT Based Crop-Field Monitoring And Irrigation Automation ", Proceedings of the 10th International Conference on Intelligent Systems and Control, ISCO 2016

[24] Mortensen, Leiv M. "Effects of air humidity on growth, flowering, keeping quality and water relations of four short-day greenhouse species." Scientia horticulturae 86.4 (2000): 299-310. 